Lexical learning and dysgraphia in a group of adults with developmental dyslexia

Anna Maria Di Betta \& Cristina Romani

Aston University

Address correspondence to:

Cristina Romani

Psychology

Aston University

Aston Triangle

B4 7ET

Birmingham UK

Tel: +44-121-3593611 x 4912

E-mail: c.romani@aston.ac.uk

Key words: developmental dyslexia, developmental dysgraphia, learning, phonological STM, phonological LTM, lexical acquisition.

Running head: LEXICAL LEARNING IN DEVELOPMENTAL

DYSLEXIA/DYSGRAPHIA 


\begin{abstract}
We investigated the ability to learn new words in a group of 22 adults with developmental dyslexia/dysgraphia and the relationship between learning and spelling problems. We identified a deficit that affected the ability to learn both spoken and written new words (lexical learning deficit). There were no comparable problems in learning other kinds of representations (lexical/semantic and visual) and the deficit could not be explained in terms of more traditional phonological deficits associated with dyslexia (phonological awareness, phonological STM). Written new word learning accounted for further variance in the severity of the dysgraphia after phonological abilities had been partialled out. We suggest that lexical learning may be an independent ability needed to create lexical/formal representations from a series of independent units. Theoretical and clinical implications are discussed.
\end{abstract}


During the last three decades a strong consensus has accumulated that a core deficit in developmental dyslexia/dysgraphia involves the short-term retention, manipulation, storage, and retrieval of phonological representations (see Share \& Stanovich, 1995; Snowling, 2000; Stanovich, 2000). Developmental dyslexic children (and more rarely adults) are impaired in tasks tapping phonological short-term memory (STM, e.g., Brady, 1991; Jorm, 1983a; McDougall, Hulme, Ellis, \& Monk, 1994), phonological awareness (for reviews see Goswami \& Bryant, 1990; Rack, Hulme \& Snowling, 1993), rapid naming (e.g., Wolf, Bowers \& Biddle, 2000), and the learning of new phonological representations (e.g., Mayringer \& Wimmer, 2000; Vellutino, Scanlon \& Spearing, 1995).

In spite of this, many questions remain unanswered. Chiefly, one may ask whether the impairments in the tasks detailed above have a single source (for example a deficit in the quality and specification of the phonological representations) or whether different impairments modulate the patterns of deficits seen in developmental dyslexia. A wealth of research has shown that spelling and reading difficulties can take different forms depending on whether correspondences between sounds and letters or stored orthographic representations are affected. Different accounts for this variation have been offered that involve either different processes and representations (for an account in the framework of a dual-route model see Castles \& Coltheart, 1993; Coltheart, Curtis, Atkins \& Haller, 1993) or different impairments to a common set of representations (for an account in a connectionist framework see Harm \& Seidenberg, 1999). Regardless of which theoretical model of reading one endorses, one should investigate whether there are different types of cognitive deficits that are linked to these different forms of dyslexia.

While deficits involving non-lexical phonological representations (deficits of phonological STM and phonological awareness) have been consistently linked to an inability to convert phonemes into graphemes and letters into sounds -so-called "phonological" dyslexia - (e.g., Snowling \& Hulme, 1989; Snowling, Stackhouse \& Rack 1986), no consistent explanation has been found for impairments involving the orthographic lexicon -socalled "surface" dyslexia - (e.g., Castles \& Coltheart, 1996; Goulandris \& Snowling, 1991; Griffiths \& Snowling, 2002; Hanley, Hastie \& Kay, 1992; Romani, Ward \& Olson, 1999). 
One possibility is that these latter impairments are the consequence of a mild phonological deficit (that is resolved in older individuals) plus some other non-specific factor. Both lower general cognitive skills (Harm \& Seidenberg, 1999) and non-cognitive factors such as poor schooling, poor motivation and poor socio-cultural opportunities (e.g., Stanovich, Siegel \& Gottardo, 1997) have been suggested. The hypothesis that a poor lexicon is mainly the result of environmental influences is supported by the finding that measures of print exposure correlate with spelling abilities in normal adults (Stanovich \& West, 1989) and with reading abilities in dyslexic children (Griffith \& Snowling, 2002). A different possibility, however, is that in some individuals poor lexical knowledge results from a specific cognitive impairment that affects the ability to create new mental representations from a set of previously unrelated units.

This paper uses a paired-associate paradigm to measure what we will call lexical learning skills. By "lexical learning" we mean the ability to set up stable and accurate mental representations of words. These representations may be either orthographic or spoken. Imparments to set up either kinds of representations will have negative consequences for fast and proficient reading and for accurate spelling, We aim to establish whether adults with poor lexical representations still suffer from a deficit of lexical acquisition when given the same learning opportunities as a control group, in laboratory conditions. We hypothesise that measures of lexical learning, together with more traditional measures of phonological skills, will help to account for variations in the severity and nature of the dyslexic impairment.

Since the seminal work of Fildes (1921), many studies have shown that dyslexic children perform poorly when they are asked to learn the association between visual stimuli (a picture or a non-sense shape) and new words over a number of learning trials (for Englishspeaking children: Gascon \& Goodglass, 1970; Nelson \&Warrington, 1980; Otto, 1961; Vellutino, Steger, Harding \& Phillips, 1975; Vellutino et al., 1995; for German-speaking children: Mayringer \& Wimmer, 2000; Wimmer, Mayringer \& Landerl, 1998; for Dutchspeaking children: Messbauer \& deJong, 2003). Three single-case studies of adults with developmental dysgraphia (Baddeley, 1993; Romani \& Stringer, 1994; Howard \& Best, 1997) have also reported difficulties in lexical acquisition, indicating that this ability remains deficient over time. 
Studies that use a picture-word associates paradigm are supported by studies which assess learning of orthographic forms in association with phonological forms (as in reading). Ehri and Saltmarsh (1995) have shown a learning deficit in disabled readers when compared to reading-age matched controls even when alphabetic knowledge was controlled for (see also Reitsma, 1983; 1989). Even more pertinently, Castles and Holmes (1996) have shown that children with poor lexical skills (measured by irregular word reading) learned more slowly than those with poor conversion rules (measured by non-word reading). Finally, Bailey, Manis, Pedersen and Seidenberg (2004) found that both surface and phonological groups of dyslexic children were slow at learning but there was an interaction between group and stimuli to be learned. The surface dyslexics (like the controls) were worse with the exception nonwords than with the regular nonwords, while the phonological dyslexics showed no difference.

Deficits in paired associate learning in dyslexia are potentially very interesting because studies with normal children have shown a relation between this task and reading which is not mediated by phonological (sublexical) skills (Aguiar \& Brady, 1991; Windfuhr \& Snowling, 2001). However, Messbauer and de Jong (2003) have reported that, although dyslexic children performed poorly in a paired associate lexical learning task, their performance was no different from the controls when a composite measure of phonological processing was covaried. They suggested that problems of phonological awareness and lexical learning reflect a single underlying phonological difficulty (and depend on the quality of phonological representations).

The present work contributes to the accumulating evidence concerning the role of new word learning in developmental dyslexia in three main ways: 1) we focused on adults; 2) we considered both spoken and written learning; and 3) we measured the impact of deficits of lexical learning on spelling after other phonological skills had been taken into consideration.

A deficit of lexical learning might be more prevalent in and more characteristic of dyslexic adults than of dyslexic children. It is well established that success in learning to read is related to awareness of the phonological units making up speech (e.g. Goswami \& Bryant, 
1990; Share \& Stanovich, 1995; Snowling, 2000; Stanovich, 2000). A child with good phonological awareness will grasp the relation between phonemes and letters more quickly and, in turn, decoding skills will lead to faster development of the orthographic lexicon (once recognised, a word will have a better chance to be remembered). However, poor phonological skills may be compensated for by memorising, one by one, new lexical items so that, with time and effort, even the lexicon of individuals with poor phonology may approximate a normal lexicon (see RE: Campbell \& Butterworth, 1985; Louise: Funnel \& Davison, 1991; KQ: Holmes \& Standish, 1996; Melanie-Jane: Howard \& Best, 1997; LD: Stothard, Snowling \& Hulme, 1996). A problem in establishing lexical representations, instead, is more difficult to compensate, especially in a non-transparent language like English where conversion rules cannot provide the right computation for many (irregular) words. Thus, deficits of lexical learning may have a stronger impact on literacy skills in dyslexic adults than in dyslexic children. Consistent with this hypothesis, there is evidence that adult poor spellers have relatively good knowledge of conversion rules, but poor orthographic lexical knowledge (e.g., Holmes \& Castles, 2001). Moreover, spelling problems are often the main complaint among adults (Bruck, 1993; Holmes \& Castles, 2001). This is also consistent with a lexical impairment. Spelling is a more sensitive probe of the quality of orthographic representations than reading since it requires a more complete and detailed representation of all the letters in the word and of their order.

Previous studies using a paired associate paradigm have only tested learning of new $\underline{\text { spoken }}$ words. Finding an impairment in learning written words in dyslexic children may seem trivial. If they have trouble deriving the phonology of novel words, they will have to learn them solely (or almost solely) as sequences of letters. This will certainly put them at a disadvantage. The adult dyslexics in our study, however, generally have problems with spelling, but not with reading, at least with untimed presentation. This suggests that they have fairly good conversion rules. ${ }^{1}$ This makes an impairment of written learning a non-trivial

\footnotetext{
${ }^{1}$ Conversion rules are more useful in reading given the asymmetric nature of
} English, which is more regular in reading than in spelling. Moreover, even the reading of irregular words can be helped by knowledge of conversion rules since possible phonological realisations and partial realisations can be checked against knowledge of existing words. 
finding. Moreover, learning of orthographic representations may be less dependent on sublexical phonological skills (such as STM and phonological awareness) than spoken learning. Thus, a written task may be better able to reveal an independent impairment. In the general discussion we will address the possibility that the learning deficit shown by the dyslexics affects either spoke representations only, orthographic representations only, or it is supramodal.

Our experimental investigation will be organised into four parts:

1) We assess the extent of the learning deficit in the dyslexics and the relation between spoken and written learning;

2) We assess the specificity of the deficit. That is, we investigate whether there are difficulties in learning tasks not involving the acquisition of new lexical representations;

3) We measure the relationship between the learning deficit and other cognitive weaknesses more traditionally associated with developmental dyslexia (i.e., poor STM, poor phonological awareness);

4) We weigh the relative contribution of various abilities to the dyslexics' spelling impairment.

\section{PARTICIPANTS}

\section{Dyslexic group}

Our dyslexic group was selected from a larger sample of adults referred to us by the Student Counselling Centre at the University of Birmingham and Aston University and by the Birmingham Adult Dyslexia Group. In spite of our attempts to recruit both dyslexic and dysgraphic adults, all the individuals referred to us complained mainly of spelling difficulties. Many of our participants were university students and this may explain why reading was not a major complaint. However, participants who were referred to us from the Birmingham Adult Dyslexia Group also complained mainly of spelling difficulties. Our experience is consistent with previous research, which suggests that spelling is a major and under-researched complaint in the adult population (Bruck, 1993; Holmes \& Castles, 2001). Using a more 
general terminology, we refer to our developmental participants as dyslexics since they do show an impairment in more taxing reading tasks with computerised presentation.

The criteria for inclusion in our study were:

1 Normal IQ (within one SD) on the Wechsler Adult Intelligence Scale-revised (WAIS-R, Wechsler, 1981).

2 Single word spelling more than two standard deviations below the control mean ${ }^{2}$.

3 No history of psychological and/or neurological problems.

Our selected dyslexic group consisted of 22 participants. Twelve had a previous diagnosis of reading/spelling problems, but a formal report was available for only one of them. In 8/22 cases (36\%) at least one first-degree relative also suffered from reading/spelling problems. Participants were tested individually at either the University of Birmingham or Aston University and attended several weekly sessions, each lasting between one and two hours. Not all of them could perform all the tasks, but an effort was made to ensure that most subjects carried out most tasks. In each session the participants carried out one spoken task and one written task. Order of presentation for modality and type of words was counter-balanced. The other tasks were presented in a semi-random order.

\section{Control group}

The same tasks given to the dyslexic participants were also given to a control group of 26 adults with no history of reading/spelling problems who were matched to the dyslexics for age and education. The controls were all native English speakers. They were tested individually at Aston University and attended between three and four sessions, each lasting about two hours. They received either course credits (for the students) or a small payment for their participation. In the case of the WAIS, the controls carried out a shortened version of the test, consisting of all the performance sub-tests and the Vocabulary sub-test.

\footnotetext{
${ }^{2}$ The spelling results of one dyslexic student fell within 2 SDs from the control mean. We regarded her performance as poor because our control group also included older and less educated participants. She was in fact -2 SDs poorer than a group of 34 fellow students.
} 


\title{
Cognitive profile
}

\author{
Method \\ Performance IQ (from the WAIS-R; Wechsler, 1981). \\ To obtain a measure of non-verbal cognitive skills, subjects were asked to carry out all the \\ non-verbal subtests of the WAIS-R. Each sub-test was administered, scored, and standardised \\ according to the guidelines of the test. A composite score (performance IQ) was computed \\ for each participant. All participants carried out these tasks.
}

\section{Vocabulary (from the WAIS-R; Wechsler, 1981)}

Subjects were asked to explain the meaning of a series of spoken words of increasing complexity (progressively less frequent and more abstract). This sub-test was administered, scored and standardised according to the guidelines of the test. All participants performed this task.

\section{$\underline{\text { Reading and spelling }}$}

All the dyslexics carried out the National Adult Reading Test (NART; Nelson, 1991), which is an untimed single word reading task. Speeded reading was also assessed with computerized tasks which used materials from Seidenberg, Waters and Barnes (1984; Experiments 3 and 4). List $1(\mathrm{~N}=142)$ contrasted words of high and low frequency and regularity. List $2(\mathrm{~N}=160)$ contrasted words and non-words obtained from the words by changing 1 to 2 letters. Thirteen dyslexics completed List 1 and sixteen completed List 2.

Word spelling was assessed using lists from: a) Schonell (1985); b) Holmes and $\mathrm{Ng}$ (1993); and c) Romani \& Ward (unpublished) which included regular and irregular words of varying frequency and length. There were 344 words in total. All the dyslexics carried out these tasks. Non-word spelling was assessed using sub-test 45 of the Psycholinguistic Assessments of Language Processing in Aphasia (PALPA; Kay, Lesser \& Coltheart, 1992), which includes 24 stimuli. Thirteen dyslexics carried out this task. The controls carried out all tasks except the NART, for which norms are available.

\section{$\underline{\text { Phonological tasks }}$}


Phonological STM. This was investigated with three tasks that asked for repetition of sequences of stimuli in serial order (digits, words, and non-words). Stimuli were presented at a rate of about one per second. In the Digit Span, the length of the sequences ranged from four to eight digits ( $\mathrm{N}=10$ for each length). Testing went on until the participant repeated correctly less than three (out of ten) sequences of a certain length or until all sequences had been attempted. For scoring, a value of 0.1 was assigned to each sequence repeated correctly. In serial recall of words, thirty sequences of five English words (concrete and abstract nouns of medium-high frequency) were used. In serial recall of non-words, thirty sequences of three non-words that respected the phonotactic constraints of the English language were used. In both serial recall tasks ten sequences consisted of monosyllabic stimuli, ten of disyllabic stimuli, and ten of polysyllabic stimuli. Performance with both words and non-words was measured by the percentage of items recalled correctly. Fifteen dyslexics carried out the Digit Span task, while eighteen carried out the Word and Non-word Serial Recall tasks.

Phonological awareness. This was investigated with two tasks classically used in developmental dyslexia. The phoneme counting task (Perin,1983) consisted of 48 stimuli: Thirty-two were real English words and sixteen were non-words. The number of phonemes varied from two to five (four items for each length). The stimuli were spoken one at a time by the experimenter. Participants were asked to report the number of phonemes in each item with no time limit. The whole dyslexic group carried out this task. The spoonerism task consisted of 87 pairs of real English words. Participants heard two spoken words and were asked to exchange the initial sounds to produce either two different words (sock-rent> rock-sent), two non-words (dare-night $>$ nare-dight), or a word and a non-word (lost-dust $>$ dost-lust). There were no time limits to respond. Each pair of words with at least one mistake was scored as an error. All dyslexics carried out this task. Two participants found the task so difficult that, in spite of trying, they could not provide answers. Thus, the task was discontinued and they were assigned the worst scores in the group.

\section{Visual memory}

WMS-R: The Visual Index (Wechsler, 1987). This is a test of visuo-spatial memory. It combines results from three tasks. In the first task, participants were presented with nonsense shapes $(\mathrm{N}=10)$ and asked to recognise them among close distractors. In the second 
$\underline{\text { task, }}$ participants were asked to learn the associations between six colours and six nonsense shapes. Initially, each nonsense shape was presented with its corresponding colour for three seconds. In the testing phase, participants were asked to point to the colour corresponding to each shape. This procedure was repeated three times $(\mathrm{N}=18)$. In the third task, participants were presented with four meaningless figures, one at a time, for ten seconds. They had to draw each figure once it was removed from sight. Performance was measured by the number of features recalled. Seventeen dyslexics carried out these tasks.

\section{Memory for stories}

Story recall (from the WMS-R; Wechsler, 1987). Participants were read two stories, one at a time, and were asked to recall each of them immediately after presentation, trying to use exactly the same wording. Performance was measured by the number of pieces of information recalled correctly. Seventeen dyslexics carried out this task.

\section{$\underline{\text { Results }}$}

Results for the dyslexics and the controls are reported in Table 1. The two groups did not differ in age, Performance IQ, or Vocabulary scores. Reading words in an untimed condition, as measured by the NART, was normal in all but three of the dyslexics (difference between IQ predicted by NART and IQ obtained by WAIS in percentile: mean $=58$; SD = 27). This task may not be sensitive enough to measure literacy skills in adults. The dyslexics performed worse than the controls in all other orthographic tasks. They spelled fewer words and nonwords accurately and they were slower and more error prone in reading words and nonwords with computerized presentation.

Insert Table 1 about here

Consistent with previous reports, the dyslexics showed a deficit on all the phonological tasks. The three STM tasks were highly inter-correlated (Digit Span vs. Word serial recall: $r=.73$; Digit Span vs. Non-word serial recall: $r=.58$; Word vs. Non-word serial recall: $\mathrm{r}=.77$; all $\mathrm{p}<.05$ ). In contrast, the dyslexics performed normally on both the Visual 
Index and the memory for stories. Performance on the Visual Index was even better if considered in terms of the age-standardised scores provided by the test (dyslexics: mean = 115; $\mathrm{SD}=12$; range=98-133; controls: mean $=100 ; \mathrm{SD}=15$ ). This last result is consistent with previous reports of normal visual memory in developmental dyslexia (Baddeley, 1993; Manis et al, 1987; Romani \& Stringer, 1994; Vellutino, Steger \& Pruzek, 1973; Vellutino et al, 1995; for a review see Jorm, 1983b).

In conclusion, the dyslexics showed a reading and spelling deficit coupled with phonological problems, but good memory for visuo-spatial patterns and for coherent stories. Therefore, the phenotypic cognitive profile of our participants is similar to that of other dyslexic children and adults reported in literature.

\section{EXPERIMENTAL INVESTIGATION}

\section{Part 1: Is There a Deficit of Lexical Learning?}

Like previous studies, we have used paired associate tasks to tap new word (lexical) learning. Differently from studies with children, however, we have used black and white drawings of real objects for which an English label already exists. Therefore, our paired associate tasks require the creation of a new label for an existing semantic representation. In this respect they are similar to tasks which involve learning the association of a novel word with a known word, which have been widely used to assess lexical acquisition in adults (e.g., Baddeley, Papagno \& Vallar, 1988; Freedman \& Martin, 2001).

Our choice of task has both advantages and disadvantages. The advantage is that we do not have to worry about how the ability to create new mental representations of nonsense pictures contributes to the task. For example, if dyslexics were very good at memorizing nonsense pictures this could blur differences with the controls. The disadvantage is that associations between an existing object and the word to be learned can be exploited in carrying out the task. For example, the pair "coset-fridge" among our stimuli could be remembered through the association with 'closet'. Similar associations, however, could be used even with nonsense pictures. More importantly, there is no reason to believe that the dyslexics and the controls would differ in their ability to exploit these potential associations. 


\section{$\underline{\text { Method }}$}

\section{$\underline{\text { Materials }}$}

Four experimental lists were administered. In each modality (spoken and written) one list was made-up of non-words constructed according to the phonotactic/orthotactic constraints of the English language, the other used Dutch words (unfamiliar to all of our participants). In the written modality, the list of non-words consisted of nine stimuli with a mean number of letters equal to $5.9(\mathrm{SD}=1.0$; range=5-8). The list of Dutch words consisted of 24 stimuli with a mean number of letters equal to $5.8(\mathrm{SD}=1.9$; range $=4-10)$. In the spoken modality, the list of non-words consisted of ten stimuli with a mean number of phonemes equal to 5.4 ( $\mathrm{SD}=1.4$; range=3-8). The list of Dutch words consisted of fourteen stimuli with a mean number of phonemes equal to $5.1(\mathrm{SD}=2.0$; range $=3-9) .^{3}$

\section{$\underline{\text { Procedure }}$}

Participants were asked to learn the association between a picture and a new word. At the beginning of the learning phase, each picture was presented along with its associated word. In the spoken version, the experimenter said the word and the participants repeated it aloud. In the written version, the word was typed below the corresponding picture and the participants wrote it down once it was removed from sight. This was repeated for the whole list. In the testing phase, participants were shown the pictures one at a time and asked to recall the corresponding word either by saying it aloud (in the spoken version) or by writing it down (in the written version). Feedback was provided in case of mistakes. Testing ended when the subject recalled the entire list correctly or after a maximum of five trials.

\footnotetext{
${ }^{3}$ In the set of written Dutch words there were a few pairs where the Dutch word carried an obvious relation with the English counterpart (e.g., vlag-flag). All the analyses involving written learning that we present were also run eliminating these few cases, but no major differences with the original analyses were found. We also found no difference if only the (English) non-words were used in the regression analyses presented later on instead of the combined set (Dutch words + non-words).
} 


\section{$\underline{\text { Results }}$}

\section{Level of performance}

Errors in the initial learning phase occurred very rarely in both groups. Performance in the test phase was measured by the mean percentage of items recalled correctly over five trials. This allowed an easier comparison among different experimental lists. We carried out a two-way ANOVA with one between-subjects factor: group (dyslexics vs. controls) and two within-subjects factors: modality of presentation (spoken vs. written) and type of stimuli (nonwords vs. Dutch words). Overall the dyslexics performed worse than the controls (all results in \% correct; dyslexics $=32.0 ;$ controls $=59.8 ; \mathrm{F}(1,46)=61.9 ; \mathrm{p}<.001)$. There was a significant effect of modality $(\mathrm{F}(1,46)=46.2 ; \mathrm{p}<.001)$, due to the fact that the spoken tasks were more difficult $($ spoken $=39$; written $=53$ ). There was also a significant effect of type of word $(\mathrm{F}(1,46)=160.8 ; \mathrm{p}<.001)$, since the Dutch words were easier than the non-words (nonwords $=38$; Dutch words $=54$ ). Only the interaction modality $\mathrm{x}$ type of word was significant $(F(1,46)=49.0 ; p .001)$. The difference between the nonwords and the Dutch words was larger in the spoken modality (nonwords $=26$; Dutch words $=52$ ) than in the written modality (nonwords $=49$; Dutch words $=57$ ). None of the interactions with group was significant indicating that the dyslexics performed similarly to the controls, although at a lower level.

Results for non-words and Dutch words correlated both in the written and spoken modality (吕slexics, written: $\mathrm{r}=.69 ; \mathrm{p}=<.001$; spoken: $\mathrm{r}=.72 ; \mathrm{p}<.001$; controls, written: $\mathrm{r}=$ $.79 ; \mathrm{p}=<.001$; spoken: $\mathrm{r}=.39 ; \mathrm{p}<.05)$. Results were averaged in each modality to obtain a measure of either written or spoken learning (written learning, dyslexics $=38 ; \mathrm{SD}=19$; controls $=68 ; \mathrm{SD}=15 ;$ spoken learning, dyslexics $=26 ; \mathrm{SD}=10 ;$ controls $=52 ; \mathrm{SD}=10$ ).

\section{Comparison of written and spoken learning}

Written and spoken learning were similarly correlated in the dyslexics and the controls (dyslexics: $\mathrm{r}=.50 ; \mathrm{p}=.02$; controls: $\mathrm{r}=.61 ; \mathrm{p}=.002$; comparison: $\mathrm{z}=.51 ; \mathrm{p}>.1$ ). We will also see that error patterns are similar, suggesting a relationship between the two tasks. Written learning was easier than spoken learning ( $\underline{\text { dyslexics }}, \mathrm{t}(21)=3.3 ; \mathrm{p}=.003$; 
controls, $\mathrm{t}(25)=7.2 ; \mathrm{p}<.001)$ in spite of the fact that the list of Dutch words was longer in the written modality. This is not surprising. Writing down words (as in written learning) requires more time and attention than repeating them and this is likely to produce better learning per trial. Collapsing across lists, the dyslexics showed a similar impairment in spoken and written learning (spoken learning $\mathrm{z}$-score $=-2.3$; written learning $\mathrm{z}$-score $=-2.0$ ).

\section{$\underline{\text { Learning curves }}$}

The percentage of items recalled correctly on each trial is reported in Figure 1. All the learning curves show a similar pattern, independent of modality and type of list. The dyslexics perform worse than the controls from the first trial onwards. Performance improves from trial to trial, but remains impaired. These results are consistent with a weakness in the encoding of new lexical representations that shows its effects from the beginning of learning and builds up over time.

Insert Figure 1 about here

\section{Error analyses}

Windfuhr and Snowling (2001) suggested that poor learning results from a problem in the process of "hooking-up" a phonological representation with its orthographic correspondent. This, in turn, would be a manifestation of a more general problem in associating linguistic and visual stimuli (see also Vellutino et al, 1975; Vellutino et al., 1995). Mayringer and Wimmer (2000) noted that a deficit of visuo-verbal association predicts a high proportion of mislabelling errors where the right name is associated with the wrong object or picture.

Method. We analysed errors from trials where the performance of the dyslexics and the controls was at a similar level (fifth and second learning trial respectively). We had complete error records for 17 dyslexics in spoken learning and for 19 in written learning. Error rates were: for spoken words, dyslexics: $57 \%(\mathrm{SD}=17)$; controls: $56 \%$ ( $\mathrm{SD}=14$; $\mathrm{F}(1,41)<1$.); for written words, dyslexics: $40 \%(\mathrm{SD}=23)$; controls: $41 \%(\mathrm{SD}=18 ; \mathrm{F}(1,43)<$ 1). We categorised the errors as: 1) "don't know"; 2) incorrect pairings, where a correct 
response was paired with the wrong picture; 3 ) fragments, where only few letters or phonemes were produced; 4) non-words, where a different non-word was produced; and (5) lexical

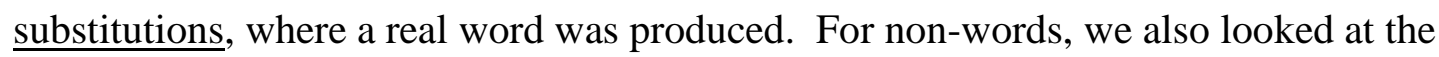
proportion of unrelated responses, that is, those containing less than $50 \%$ of the target segments.

Results. The distribution of errors is reported in Table 2. It is similar in the two groups. The only exception is in the proportion of “don't know" responses which was higher in the controls. The difference was significant in the written modality $(\mathrm{F}(1,43)=4.6 ; \mathrm{p}=.04)$ and it approached significance in the spoken modality $(\mathrm{F}(1,41)=3.0 ; \mathrm{p}=.09)$. This is probably because the controls were only on their second recall trial. Crucially, the two groups did not differ in terms of incorrect pairings (both spoken learning and written learning, $\mathrm{F}<1$ ). This is similar to what has been reported by others (Mayringer \& Wimmer, 2000; Messbauer \& deJong, 2003; Vellutino et al., 1975).

Insert Table 2 about here

Mayringer \& Wimmer (2000) reported that the errors produced by dyslexic children in word learning generally preserve the syllabic structure of the target while changing the identity of some of the segments. To investigate this, we pooled all the non-word and word errors. Replicating what was found by Mayringer and Wimmer (2000), the dyslexics preserved number of syllable as much as the controls (spoken learning: dyslexics: 59\%; $\mathrm{SD}=$ 29; controls: $72 \% ; \mathrm{SD}=23 ; \mathrm{F}(1,41)=2.8 ; \mathrm{p}=.1$; written learning: dyslexics: $72 \%$; $\mathrm{SD}=22$; controls: $78 \% ; \mathrm{SD}=22 ; \mathrm{F}(1,43)<1)$. Consonant-vowel sequence was also similarly preserved (spoken learning: dyslexics: $33 \%$; $\mathrm{SD}=27$; controls, $36 \% ; \mathrm{SD}=25 ; \mathrm{F}(1,41)<1$; written learning: dyslexics: $37 \%$; $\mathrm{SD}=15$; controls: $37 \%$; $\mathrm{SD}=21 ; \mathrm{F}(1,43)<1)$. 


\section{Delayed recall after learning to criterion}

Still another learning task was given to a subgroup of dyslexics and controls (spoken learning was carried out by 12 dyslexics and 15 controls; written learning by 10 dyslexics and 17 controls). This time we used Italian words, which were unfamiliar to all participants. Learning was continued until $100 \%$ of the words were recalled correctly two consecutive times and retested unexpectedly after a week. The lists presented for spoken and written learning had the same number of words $(=10)$ and the words were matched for syllable, phoneme and letter length. Learning was again difficult for the dyslexics (mean z-score: $\underline{\text { spoken }}=-2.0 ; \mathrm{SD}=0.4$; $\underline{\text { written }}=-1.7 ; \mathrm{SD}=0.9$ ) and took the dyslexics many more trials than the controls (mean z-score: $\underline{\text { spoken }}=+5.3 ; \mathrm{SD}=2.9$; $\underline{\text { written }}=+3.1 ; \mathrm{SD}=2.6$ ). Moreover, in spite of many more learning opportunities, after a week the dyslexics were, again, significantly worse than the controls (mean z-score: $\underline{\text { spoken }}=-2.7 ; \mathrm{SD}=1.1$; written $=$ $-3.0 ; \mathrm{SD}=1.4)$.

\section{$\underline{\text { Discussion }}$}

Our results extend and complement the data present in literature by showing that problems in learning new lexical representations affect not only dyslexic children, but also dyslexic adults, and that they affect not only spoken words, but also written words. Furthermore, this learning problem does not disappear given more learning opportunities. As shown by the experiment with Italian words, long-term recall of words learned to criterion is also impaired. This is consistent with more fragile/unstable representations in the dyslexics. It remains to be demonstrated whether retrieval of more consolidated representations is normal.

In light of our results it may be surprising that none of the adult dyslexics in the present study reported difficulties in acquiring spoken language. However, we have only anecdotal reports. Consistent with our findings of a deficit of lexical learning, a number of recent longitudinal studies have documented delayed language acquisition in children at risk of dyslexia (e.g., Elbro, Borstrom \& Petersen, 1998; Gallagher, Frith \& Snowling, 2000; for a review see Stackhouse, 1996). 
Our results offer some preliminary insights into the nature of the learning deficit. The hypothesis of a difficulty in associating verbal and visual stimuli is not supported by our error analysis. The dyslexics produced a low proportion of incorrect pairings, like the controls. The strong correlation between the two learning tasks and the similarity of the error patterns suggest a common underlying deficit. The good preservation of syllabic structure suggests, moreover, that the deficit is not in setting up syllabic frames. Results, instead, are consistent with an impairment that affects the ability to encode and retain the formal aspects of linguistic representations, whether they consist of sequences of phonemes or letters. If this hypothesis is correct, the dyslexics should have no problems learning other kinds of representations. This will be addressed in the next section.

\section{Part 2: How Specific is the Learning Deficit?}

In this section we assess the specificity of the dyslexics' learning deficit by looking at their performance in two types of tasks: one which involves learning associations between real (known) words and the other which involves learning the association between pictures and sequences of non-linguistic symbols. Since real words can be remembered through their meanings as well as through their phonology, we expect the dyslexics' performance to be normal or close to normal. We may also expect performance to be good in the second type of task. Our dyslexics performed well on tasks of visuo-spatial memory (Visual Index; see earlier). However, single-case studies have shown dissociations between good memory for spatial relations between the parts of a single object and poor memory for sequences of nonlinguistic visual units (see AW: Romani et al, 1999). Thus, the dyslexics could still have problems in this second type of task. Finally, we administered a standardised task which directly compared memory for new words with different forms of visual memory.

\section{$\underline{\text { Method }}$}

\section{Learning a list of words}

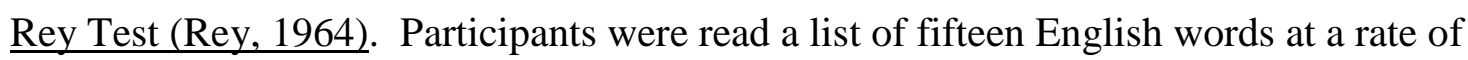
one per second and asked to recall as many as possible in any order. This procedure was repeated five times. A recall of the list was attempted after 20 minutes of filled delay (delayed recall). All but one of the dyslexics carried out this task. 
Word Pairs-WMS (Wechsler, 1987). Participants had to learn the association between eight pairs of English words. Four were "easy" since the words were semantically related (e.g., baby-cry), four were "difficult" since the words were unrelated (e.g., cabbage-pen). First the pairs were read one at a time. During the testing phase, participants were presented with the cue word and asked to recall the paired word. The whole procedure was repeated three times $(\mathrm{N}=24)$. Seventeen dyslexics carried out this task.

\section{Learning new visual sequences}

Learning of Russian words. This task used six sequences of Cyrillic characters, each paired with a picture. Since all our subjects were unfamiliar with this alphabet, Russian words were closer to sequences of visual symbols than to linguistic objects. The procedure and the scoring method were the same as that used in learning non-words and Dutch words. The mean number of symbols per word was equal to 3.8 ( $\mathrm{SD}=0.4$; range=3-4). The entire dyslexic group carried out this task.

\section{Contrast between visual and verbal learning}

The Doors and People Test (Baddeley, Emslie \& Nimmo-Smith, 1994). It contrasts visual and verbal tests of both recall and recognition. The visual recall test is a test of visuospatial memory. Participants are asked to copy a series of four designs and then to draw them from memory after a filled delay. The visual recognition test involves viewing two series of photographs of doors ( $\mathrm{N}=12$ each). Then, participants have to recognise each target door among a group of four very similar doors. What kinds of memory resources are necessary for this sub-test is less clear, but it contrasts with other visual tasks in that good performance depends on veridical memory for details.

The verbal recall sub-test involves learning the proper (unknown) names of four characters. They are presented initially in association with photographs and a job description (e.g., "This is the minister. His name is Cuthbert Cattlemore"). Participants had to recall the name after being given the job immediately after presentation and again after a filled delay. In the verbal recognition sub-test participants read two series of names ( $\mathrm{N}=12$ each) and then attempt to recognise each of them among three orthographically/phonologically similar 
distractors (Diane Nabney; among Diane Neeson, Diane Norfar and Diane Nusse). Fifteen dyslexics carried out this test.

\section{$\underline{\text { Results }}$}

Performance on the word learning tasks was normal (Word Pairs Test: dyslexic mean $=21 ; \mathrm{SD}=3 ;$ control mean $=22 ; \mathrm{SD}=2 ; \mathrm{F}(1,41)=3.6 ; \mathrm{p}=.07$; Rey Test: dyslexic mean $=$ 58; $\mathrm{SD}=9 ;$ control mean $=57 ; \mathrm{SD}=8 ; \mathrm{F}(1,45)<1)$. In the Rey test the dyslexics were very close to the controls at each learning trial and after the delay. With the Russian words, instead, the dyslexics obtained worse results (mean percentage correct: dyslexics: $28 ; \mathrm{SD}=13$; controls: 38; $\mathrm{SD}=19 ; \mathrm{F}(1,46)=4.45 ; \mathrm{p}=.04)$. Performance, however, was better than for learning spoken and written words (comparing $\mathrm{z}$ scores, $\mathrm{t}(21)=8.9 ; \mathrm{p}<.001$ and $\mathrm{t}(21)=5.7$; $\mathrm{p}<.001$, respectively).

Contrast between visual and verbal learning: Doors and People Test. In the visual $\underline{\text { sub-tests, }}$, the dyslexics performed very similarly to the controls (recognition raw scores: dyslexic mean $=20 ; \mathrm{SD}=3$; control mean $=21 ; \mathrm{SD}=2 ; \mathrm{F}(1,38)=2.6 ; \mathrm{p}>.1$; recall raw scores: dyslexic mean $=46 ; \mathrm{SD}=2$; control mean $=46 ; \mathrm{SD}=3 ; \mathrm{F}(1,38)<1)$. In contrast, they performed poorly on the verbal sub-tests (recognition raw scores: dyslexic mean $=17$; $\mathrm{SD}=5 ;$ control mean $=21 ; \mathrm{SD}=3 ; \mathrm{F}(1,38)=7.2 ; \mathrm{p}=.01$; recall raw scores: dyslexic mean $=$ 35; $\mathrm{SD}=7$; control mean $=43 ; \mathrm{SD}=4 ; \mathrm{F}(1,38)=25.2 ; \mathrm{p}<.001)$. Overall, the dyslexics' results closely mirror those of SR, the dysgraphic subject reported by Baddeley (1993).

\section{$\underline{\text { Discussion }}$}

The dyslexics do not suffer from a generalised learning impairment. Memory for visuo-spatial patterns (measured by the Visual Index of the WMS-R and the visual recall subtest of the Doors and People test) and memory for visual details (measured by the recognition sub-test of the Doors and People test) were normal. The verbal learning deficit was also very specific since it was restricted to one aspect of words: their form. Performance was much better when word meanings were involved. Our findings contrast with those of Messbauer and deJong (2003) who found similar impairments with word and non-word learning. They are consistent, however, with other results from the literature. Vellutino and collaborators reported that in word-picture associate tasks dyslexics performed relatively better than 
controls with concrete than abstract words (Vellutino \& Scanlon, 1985) and with known words compared to real but unfamiliar words (Vellutino et al., 1995). Mayringer and Wimmer (2000) also reported that their dyslexic children performed poorly with either new words or uncommon proper names, but normally with short, common names. All these results are consistent with a specific problem in encoding the formal properties of words, but not their meanings.

Results with the Russian words were more ambiguous. Performance was impaired, but much better than in the other new word learning tasks. Performance, however, could be facilitated by the limited set of symbols in each word (between 3 and 4), which could favour memorization as integrated visual patterns. There is evidence that the dyslexics rely more on visual memory in carrying out the learning tasks. The Visual Index showed a high correlation with both the Russian words $(\mathrm{r}=.76 ; \mathrm{p}<.001)$ and written learning ( $\mathrm{r}=.60 ; \mathrm{p}=.01)$. These correlations were weaker in the controls, although not significantly so (Russian words: $\mathrm{r}=.45$; $\mathrm{p}=.02$; written learning: $\mathrm{r}=.38 ; \mathrm{p}=.06$; difference with the dyslexics: $\mathrm{z}=1.5$ and $0.9 ; \mathrm{p}>.05$ ). Moreover, in the dyslexics, there was no correlation between the Russian word task and the lexical learning tasks $(r=.22-.35)$, unlike the controls where they were correlated $(r=.45-.62)$. This suggests that the dyslexics learn the Russian words by relying more on their spared visuo-spatial memory and less on phonology and sequential memory.

\section{Part 3: Is the Deficit of Lexical Learning an Independent Deficit?}

Our results suggest a specific learning deficit in the dyslexics. A crucial question at this point is whether this deficit is primary or secondary to the phonological impairments that have been associated with developmental dyslexia/dysgraphia.

The acquisition of orthographic representations begins at a time when a child has already developed a spoken lexicon and most of the newly encountered written words are well known in their phonological form. Therefore, it is reasonable to assume that the orthographic lexicon is parasitic on the phonological one to a certain extent. Ehri $(1992 ; 1998)$ has suggested that, ultimately, lexical representations are stored in memory as an "amalgamation" of phonological and orthographic information, in which the sequence of letters is anchored in a systematic way to the sequence of phonemes. Accordingly, Mayringer and Wimmer (2000) 
have proposed that a problem with phonological memory causes poor orthographic learning. If the phonological representations are not well specified, problems with orthographic representations will follow. In turn, problems with phonological learning could stem from problems of phonological STM and/or problems of phonological awareness, which are well known in developmental dyslexia.

Phonological STM has been shown to be associated with the ability to carry out paired associate tasks involving new words, but not familiar words, both in normally developing children (Gathercole \& Baddeley, 1990; Gathercole, Hitch, Service \& Martin, 1997; Michas \& Henry, 1994) and in adults (Atkins \& Baddeley, 1998; Papagno, Valentine \& Baddeley, 1991; Papagno \& Vallar, 1992; for a review see Baddeley, Gathercole \& Papagno, 1998). Furthermore, deficits of STM (both acquired and developmental) lead to impaired lexical acquisition (Baddeley et al., 1988; Hanten \& Martin, 2001). This indicates that good short-term phonological traces are necessary for long-term acquisition. Given that deficits of STM are pervasive in developmental dyslexia, it is natural to attribute deficits of phonological learning to them. However, correlations between phonological learning and STM have been reported by some studies (Maringer and Wimmer, 2000), but not by others (Windfuhr \& Snowling, 2001; de Jong, Seveke \& van Veen, 2000). Likewise, a relation between STM and lexical learning was found in one single case of developmental dyslexia (SR: Baddeley, 1993) but not in another (AW: Romani \& Stringer, 1994; Romani et al., 1999).

The same inconsistent relation has been shown between phonological awareness and lexical learning. Some studies with normal and dyslexic children have reported an association (de Jong, et al., 2000; Messbauer \& de Jong, 2003; Windfuhr \& Snowling, 2001). In addition, it has been shown that training phonological awareness enhances the ability to learn new words (de Jong et al., 2000; Torgesen, Morgan \& Davis, 1992) and that controlling for phonological processing eliminates differences in lexical learning (Messbauer \& de Jong, 2003). However, no association between phonological awareness and lexical learning was found by Mayringer \& Wimmer (2000) in dyslexic children. Moreover, a number of developmental cases with impaired orthographic lexical representations (surface dysgraphia) have shown no detectable impairment of phonological awareness (Allan: Hanley et al., 1992; MI: Castle \& Coltheart, 1996; and AW: Romani et al., 1999). 
It is possible that lexical learning, phonological STM and phonological awareness are related, but independent abilities. Segmentalised representations and the ability to retain them in the short term may be prerequisites for their long-term learning. Something else, however, may also be necessary and this could be the ability to create a unified new representation from a series of independent units. This hypothesis may explain why correlations are found inconsistently in groups of dyslexics, where selective impairments of either lexical learning or STM/phonological awareness may weaken the association seen in normal children. If this hypothesis is correct, one should find positive correlations, but also individual cases showing dissociations. In contrast, if phonological skills are responsible for poor learning no such dissociations should be found. Moreover, there should be correlation between phonological skills and lexical learning whether the learning task is written or spoken.

\section{$\underline{\text { Results }}$}

In the dyslexics, a composite STM score (average z scores of the three STM tasks) showed a strong correlation with spoken learning $(r=.61 ; p<.001)$, but not with written learning $(\mathrm{r}=.16 ; \mathrm{p}=.56){ }^{4}$ In the controls, STM showed a modest correlation with both of the learning tasks (spoken: $\mathrm{r}=.35 ; \mathrm{p}=.08$; written: $\mathrm{r}=.39 ; \mathrm{p}=.05$ ). Phoneme counting showed no significant correlation in either group ( $\underline{\text { dyslexics: }}$ spoken learning $r=11 ; p=.63$; written learning $\mathrm{r}=-.001 ; \mathrm{p}=.1$; controls: spoken learning $\mathrm{r}=.05 ; \mathrm{p}=.81$; written learning $\mathrm{r}=.15 ; \mathrm{p}=$ .46). In the dyslexics, spoonerisms showed moderate correlations with spoken and written learning (spoken: $\mathrm{r}=.50 ; \mathrm{p}=.02$; written: $.46 ; \mathrm{p}=.03$ ). In the controls, the spoonerisms correlated with STM $(r=.46 ; \mathrm{p}=.02)$, but not with the learning tasks (spoken: $r=.14$; written: $r=.15$; all $p>.1$ ). Figure 2 shows the relation between the lexical learning tasks and either phonological STM or phonological awareness (a composite score which averages results on the two tasks). Discrepant cases where poor lexical learning is not accompanied by poor phonological skills have been highlighted.

\footnotetext{
${ }^{4}$ For three dyslexics who did not carry out the Digit Span task, this was calculated according to the following stepwise regression equation (Digit $\mathrm{Span}=2.5+0.05$ Word Serial recall; $\mathrm{F}(1,13)=14.5 ; \mathrm{p}=.002)$.
} 
Insert Figure 2 about here

\section{$\underline{\text { Discussion }}$}

Consistent with expectations, we found significant correlations between STM/phonological awareness and spoken learning. Moreover, none of the dyslexics showed poor phonological STM and good lexical learning. Thus, good short-term memory is needed for long-term learning. Something else, however, seems to be needed. Two of our participants had only a mild impairment of phonological STM, but a severe impairment of spoken learning. A further two had completely normal STM, but severe impairments of written learning.

The strongest dissociation was shown by RG, who performed completely normally in tasks of both phonological awareness and STM (z-scores: spoonerisms $=0.0$; phoneme counting $=-0.2 ;$ STM score $=+1.2$ ). Consistently, RG also had good ability to use conversion rules (he produced the majority of his spelling errors on irregular words, and most of these errors were phonological in nature). In spite of this, his written learning was very poor (z-score $=-2.1)$. In addition, RG performed well with the Russian words (z-score = +0.3 ), which can be taken as an indirect indication of good visuo-spatial memory (he did not carry out the Visual Index), and in other tasks which required associations (Rey test: z-score = +0.1 ). In all aspects of performance, RG provides a good replication of AW (Romani \& Stringer, 1994; Romani et al., 1999). Cases like RG and AW are quite rare. Their existence, however, suggests that the capacity to learn new words--to store them as semi-permanent lexical items--involves resources that are distinct from those used to retain them in the shortterm.

In the dyslexics, we found no correlation between written learning and STM and only a moderate correlation with phonological awareness. In the controls, there was no correlation between lexical learning (either spoken or written) and phonological awareness. These results contrast with studies of children and suggest that phonological awareness may play a smaller role at a later developmental stage when most participants have reached a sufficient level of segmental specification. 
Differences in lexical learning once phonological processing is considered.

Messbauer and de Jong (2003) suggested that poor new word learning in developmental dyslexia is not an independent deficit because differences from chronological age-matched controls disappeared when they covaried a composite measure of phonological processing. We followed their same procedure. We ran a principal components analysis on the data from the five STM and phonological awareness tasks. This yielded one factor with an eigenvalue greater than one, which accounted for $68 \%$ of the variance and received high loadings from all tasks $($ Digit Span $=86 \%$; Word serial recall $=88 \%$; Non-word serial recall $=88 \%$; Phoneme Counting $=62 \% ;$ Spoonerisms $=86 \%$ ). From this analysis we derived a phonological processing score for each participant. Then we ran ANOVAs on the scores for spoken learning and written learning, with subject group as a between-subjects factor and phonological processing as a covariate. There were significant effects of phonological processing on both spoken and written learning $(\mathrm{F}(1,45)=13.3 ; \mathrm{p}=.001$, and $\mathrm{F}(1,45)=6.6 ; \mathrm{p}$ $=.01$, respectively). However, the difference in learning ability remained significant even when phonological processing was taken into account (spoken learning: $\mathrm{F}(1,45)=18.2 ; \mathrm{p}<$ .001 ; written learning: $F(1,45)=7.4 ; p=.009)$. These results are in contrast to those of Messabauer and de Jong (2003), but are consistent with those of Windfuhr and Snowling (2001), who reported independent effects of lexical learning and phonological processing on reading in normally developing children.

\section{Summary of Results}

We have described the performance of a group of dyslexic adults on a variety of tasks. Table 3 summarises our findings up to this point. It reports the dyslexic average $\mathrm{z}-$ score, together with the level of statistical significance of the comparison with the control group.

Insert Table 3 about here 
The dyslexics were poor on all the tasks of new word learning (including the verbal recall and recognition sections of the Doors and People Test), on all the phonological tasks, and, to a lesser extent, on the Russian word learning task. The next section will examine how these different abilities contribute to predict spelling.

\section{Part 4: Patterns of Relations among Tasks: Predicting spelling}

An important point that remains to be established is whether the lexical learning problem that we have highlighted in our dyslexics predicts the severity of their dysgraphia and whether such relation is independent of other variables. In the dyslexics, spelling correlates with all tasks tapping formal lexical learning (spoken learning: $r=.59 ; \mathrm{p}=.004$; written learning: $\mathrm{r}=.63, \mathrm{p}=.002$; the Doors and People verbal recall test; $r=.52 ; \mathrm{p}=.05)$. In addition, it correlates with a measure of phonological short-term memory (the STM score: $\mathrm{r}=$ $.62 ; \mathrm{p}=.006)$, with the spoonerisms $(\mathrm{r}=.47 ; \mathrm{p}=.03)$ and the Visual Index of the WMS, which taps visuo-spatial memory $(\mathrm{r}=.56 ; \mathrm{p}=.02)$. The correlation with tasks tapping lexical-semantics are generally smaller (word pairs: $r=.47 ; p=.06$; Rey test: $r=.19 ; p>.1$; story recall: $\mathrm{r}=.46 ; \mathrm{p}=.06)$.

In the controls, the only task to correlate significantly with spelling was the Vocabulary subtest of the WAIS $(\mathrm{r}=.58 ; \mathrm{p}=.002)$. It is possible that this lack of correlation is due to reduced variability. Alternatively, it is possible that, in the control group, differences in lexical knowledge are due to environmental influences (e.g., education, print exposure; occupation) more than to genetically determined abilities.

To further explore the independent contribution of lexical learning deficits to spelling we ran a series of stepwise regression analyses. We entered performance IQ at the first step. The STM score, the phonological awareness composite score (average of the z-score in the two phonological awareness tasks), spoken learning and written learning were entered at either step two or three. Results are reported in Table 4. When entered after performance IQ, all four variables made a significant contribution. When entered last, STM and the learning tasks, but not the phonological awareness composite score, still accounted for further variance. Results did not improve if the spoonerisms alone were used instead of the composite phonological awareness score. 
Insert Table 4 about here

These results suggest that, together with phonological skills, lexical learning taps unique resources associated with spelling. Our results could seem to contrast with a great number of studies which have shown a strong relationship between measures of phonological awareness and reading acquisition in children (e.g.; Goswami \& Bryant, 1990; Wagner \& Torgesen, 1987) and with a smaller number of studies showing a similar relation with spelling (Griffith, 1991; Leong, 1999; Perin, 1983). It is to be noted, however, that the contribution of phonological awareness to reading decreases rapidly over development (see Badian, 1995, 2000; de Jong \& van der Leij, 1999). Likewise, training phonological awareness yields diminishing returns on reading and spelling after preschool (Bus \& van Ijzendoorn, 1999; Ehri, Nunes, Willows, Valeska Schuster, Yaghoub-Zadeh \& Shanahan, 2001).

\section{GENERAL DISCUSSION}

Two recent papers have rekindled interest in an impairment of lexical acquisition in developmental dyslexia/dysgraphia (Mayringer \& Wimmer; 2000; Messbauer \& de Jong, 2002). Like these studies, we have assessed lexical learning with a task involving learning new words in association with pictures. Differently from these studies, we focused on English adults who came to us primarily because of spelling problems. In spite of the different population, we also found a significant impairment compared to matched controls.

In agreement with the results of Mayringer and Wimmer (2000), but not with Messbauer and de Jong (2003), the learning deficit affected new words, but not familiar words. Also in contrast with Messbauer and de Jong, the dyslexics continued to show a deficit after phonological abilities were factored out. This second difference is consistent with lexical learning abilities being less dependent on phonological abilities in adults than in children. It is also possible that problems of lexical learning have a different impact in different orthographies with a more significant impact in a non-transparent language like English than in a more transparent language like German. 
Our results are consistent with others which point to failures in orthographic lexical knowledge in developmental dyslexia (Badian, 1995, 2000; Cunnigham, Perry, Stanovich \& Share, 2002; Cunningham \& Stanovich, 1993; Griffiths \& Snowling, 2002; Holmes \& Castles, 2001; Stanovich, 1992). In addition, they argue that poor orthographic lexical knowledge (at least in a good portion of adult dyslexics) is not related to either generally low cognitive abilities or environmental factors (such as poor socio-economic conditions, poor education, etc). The dyslexics who participated in the present study were all very motivated individuals with age, education and IQ comparable to that of the controls. In spite of this, they performed worse in controlled experimental conditions when they had to learn the formal aspects of new lexical items. This is at odds with the hypothesis that an impoverished reading experience is the cause of their dyslexia. In addition, they were unimpaired when learning involved visuo-spatial configurations, visual details, or lexical-semantic representations. This is contrary to a generalized cognitive impairment. Our findings do not exclude print exposure as a factor that affects the extent and quality of lexical knowledge (e.g., see Cunningham \& Stanovich, 1993), but they suggest that something else is involved, at least among dyslexics.

Finally, our results show that lexical learning tasks are good predictors of spelling abilities in developmental dyslexia and account for spelling variation even after the contribution of phonological abilities is partialled out. In a further paper (Romani, di Betta \& Olson, in preparation), we will show that lexical learning is similarly related to word reading (while no association is present with nonword reading and spelling). This raises the possibility that lexical learning tasks can be used successfully to increase our ability to predict and diagnose dyslexic/dysgraphic impairments. They may be especially useful to diagnose children with good conversion rules who would be identified as dyslexics only when the role of decoding abilities fades over development (see Badian, 2001, for a similar hypothesis of cases of "late discovery" of dyslexia). Written learning and learning of signs might also be used to help diagnose dyslexia in deaf children where phonological tests are not possible.

We have argued that poor lexical learning stems from a specific problem. We will now consider different hypotheses concerning what underlies this impairment.

\section{The nature of the underlying deficit/s}


A problem of visuo-verbal association. The dyslexics did not produce any more incorrect pairings than the controls on the learning tasks. In addition, they performed poorly in both the recall and recognition tasks of the Doors and People Test, which involve memory for names, but do not involve any inter-stimulus association (see alsoVellutino et al., 1995 for similar impairment in paired associate tasks and free recall). These results do not support the hypothesis of a problem in the process of "hooking up" a phonological representation with its orthographic correspondent. Instead, they suggest a problem in learning the new words themselves (see also Ellis \& Miles, 1981; Mayringer \& Wimmer, 2000).

Poor conversion rules. Good reading in untimed conditions suggests relatively intact conversion rules ${ }^{5}$. Still, individuals with better conversion rules could use them more efficiently to recall the regular parts of words and focus attention on the irregular parts. However, in a similar group of dyslexics (Romani, et al., in preparation) we found that: a) written learning did not correlate with the ability to use conversion rules in spelling; $b$ ) individuals with good conversion rules still showed poor written learning and, finally c) written learning made an independent contribution to the severity of dysgraphia after conversion rules were taken into account. Thus, a difficulty with written lexical learning cannot be explained by poor conversion rules.

A phonological sub-lexical impairment. This would refer to an inability to manipulate and/or retain speech sounds which do not correspond to whole words. Correlations between phonological awareness and lexical learning were inconsistent across groups and tasks. Phonological STM, instead, was strongly related to spoken learning. Thus, a deficit in the short-term retention of speech sounds could cause and an impairment of spoken learning which, in turn, could cause poor orthographic learning. Contrary to this hypothesis, however, we found no correlation between STM and written learning in the dyslexics. This could be explained, in part, by their preference for using a visual strategy. Still, one would expect at

\footnotetext{
5 The dyslexics were poor at non-word reading. However, we mixed together, in a task which emphasized speed, non-words and words very similar to each other. This promoted lexical errors. We think that the dyslexics would have performed much better in an untimed reading task which just included non-words.
} 
least a modest correlation if phonological STM is ultimately the cause of the learning deficit, especially given the range of STM abilities shown by our subjects. Moreover, the hypothesis that poor learning is caused by poor STM leaves cases like RG and AW unexplained (Romani et al., 1999). These individuals had good STM and poor learning. Finally, this hypothesis is not supported by the fact that the dyslexics continue to display a significant impairment in lexical learning (both spoken and written) even when a composite score of phonological abilities is factored out.

We can conclude that problems with lexical learning are not caused by sublexical phonological problems. A separate impairment in setting up and/or retaining good quality lexical representation must be implicated. To pinpoint the exact nature of this 'lexical learning' impairment, however, is more difficult.

A phonological lexical learning impairment. One hypothesis is that the impairment is one of phonological memory. Poor written learning would be the consequence of poor spoken learning because phonological representations may be preferred for long-term retention of verbal information as well as for short-term retention. Thus, even when subjects are given orthographic representations to learn, they would normally do so with the help of phonological representations. The correlation between written and spoken learning supports this interpretation. In the dyslexics, written learning does not correlate with other phonological tasks. However, the dyslexics--who have an impaired phonology--may rely more on visuo-spatial skills to carry out this task. Similarly written learning may explain spelling variance that is not accounted for by spoken learning because written learning taps both the lexical (phonological) learning ability and visuo-spatial memory (which are both exploited in learning word spellings).

The phonological impairment we are considering here is different from one of phonological STM since it would involve the consolidation of memory traces rather than their temporary activation. Equally, this impairment may not affect the quality of phonological representations after they have been properly set up. Creating a new lexical representation may take longer than normal, but after a certain amount of extra practice lexical processing can take place completely normally (contrary to the hypothesis of generally underspecified 
phonological representations; e.g., Snowling, 2000). This would create (normal) fluent speech when sufficiently familiar lexical items are used even if the task is taxing. It would also create the difference between spelling and spoken speech since the latter is more practiced. Further experimental work which manipulates frequency and type of task (e.g., requiring either lexical access or taxing segmental manipulations) is necessary to address these questions.

A visual lexical learning impairment. An alternative hypothesis is that developmental dyslexia involves visual difficulties in processing and encoding sequences of units (see also Badian, 1995, 2000; Holmes \& Castle, 2001) in addition to well documented phonological difficulties. The hypothesis of a second visual factor in dyslexia has a long history (for a review, see Lovegrove, 1996). However, our results point specifically to impairments of visuo-sequential memory rather than to more general impairments of visual memory. Visuospatial memory is not only good in our dyslexic group, but it is used in a compensatory way to aid learning. The hypothesis of a deficit of sequential memory is supported by the impairment shown by the dyslexics with the Russian words. It is difficult for the phonological hypothesis to explain this impairment.

The hypothesis of an impairment of visuo-sequential memory fits well with some reports by Frith (1985) that "unexpectedly poor spellers" (whose reading is relatively unimpaired) read by partial cues (for example, they are less affected than the controls in reading passages with obliterated letters). This reading strategy may be caused by a deficit of visuo-sequential memory which induces them to rely too much on global/holistic processing of word shape at the expense of a more complete analytic processing of letter sequences (see also Seymour \& MacGregor, 1984). Such a strategy may be efficient for reading, but not for spelling, which requires more detailed information about letter sequences. Finally, this hypothesis is consistent with the case of AW who had a selective spelling impairment and performed poorly in tasks involving memory for sequences of Hindi and Japanese symbols, particularly when presentation was sequential, thus making the integration of the symbols into a unitary visual shape more difficult (Romani et al., 1999). 
A more abstract lexical learning impairment. Finally, it is possible that problems of phonological and orthographic learning are due to a common deficiency in making lexical items from a set of unrelated units (be they phonemes, letters, signs or symbols of any kind). We may be endowed with a human-specific capacity that allows the encoding/storage of thousands of different representations all made up by combining, in different orders, a limited set of segments. At first, this ability may be applied to encode and store phonological representations, but it can be relevant to other domains, such as written language, which are newer in evolutionary terms. Some dyslexics may have less of this capacity and this may explain their poor lexical representations. This hypothesis is consistent with both the correlation between spoken and written learning and the impairment shown with the Russian words. It is also consistent with a long history of reports showing problems with tasks involving processing and retention of sequences in developmental dyslexia (for group studies see: Bryden, 1972; Corkin, 1974; Farmer \& Brison, 1989, reported in Farmer \& Klein, 1995; Holmes \& Ng, 1993; Mason, 1980; for single case studies see: Romani et al., 1999; Goulandris \& Snowling, 1991).

Different hypotheses regarding the lexical learning impairment make different predictions to be tested by further studies. The hypothesis of a visuo-sequential impairment predicts correlations between visuo-sequential tasks on the one hand and spelling and written learning on the other. The hypothesis of a phonological impairment predicts, instead, correlations between lexical learning tasks and taxing word production tasks. Finally, the hypothesis of a supra-modal impairment predicts inter-correlations among all of these types of tasks.

Implications for computational models. In so-called dual route models of reading, little is said about how either phoneme-grapheme conversion rules or lexical entries are acquired. Connectionist models, instead, are very well suited to explore these issues. This has been accomplished in the so called triangular model of reading which includes a phonological, an orthographic, and a semantic component interconnected through hidden units (Harm and Seidenberg, 1999; Plaut, McClelland, Seidenberg and Patterson, 1996; Seidenberg \& McClelland, 1989) One may ask, therefore, how such a model could account for our results. 
Using the triangle model, Harm and Seidenberg (1999) simulated phonological dyslexia by impairing the phonological component of the model (which represents the regular mappings between phonology and orthography, and, therefore, is crucial for nonword processing). Surface dyslexia instead, was simulated by impairing the model's learning efficiency. This second hypothesis has clear affinity to our proposal. The challenge for the triangle model (or any other model), however, is to simulate a learning impairment that, on the one hand, is very selective but, on the other hand, is general enough to encompass a genetically-based ability that must be used for purposes other than orthographic processing. The specificity requirement rules out simulations based on a general reduction of the learning rate or on degradation of the visual input. The generality requirement rules out simulations that only affect the mapping between phonemes and graphemes.

\section{Conclusions.}

We have described a selective deficit in learning new lexical items in a group of adults with developmental dyslexia which is independent of more traditional phonological impairments. Different specific hypotheses of the nature of this deficit have been suggested. All of them, however, entail a deficit in encoding and/or retaining sequences of units (phonological, visual or more abstract). Learning models that have been applied to dyslexia to date are unable to represent a deficit of this type since they do not include a sequencing mechanism (all words are monosyllabic and order within the syllable is represented using units which are position specific). Future experimental and computational studies should explore a possible additional learning impairment in developmental dyslexia considering as a starting point the characteristics highlighted by our study: it is not due to lack of training; it is very specific and yet is caused by a weakness which has a genetic basis. 


\section{REFERENCES}

Aguiar, L., \& Brady, S. (1991). Vocabulary acquisition and reading ability. Reading and Writing: An Interdisciplinary Journal, 3 , 413-425.

Atkins, P.W.B., \& Baddeley, A. (1998). Working memory and distributed vocabulary learning. Applied Psycholinguistics, 19, 537-552.

Baddeley, A. (1993). Short-term phonological memory and long-term learning: A case study. European Journal of Cognitive Psychology, $\underline{5}$ (2), 129-148.

Baddeley, A., Emslie, H., \& Nimmo-Smith, I. (1994). Doors and people: A test of visual and verbal recall and recognition. Bury St Edmunds, England: Thames Valley Company.

Baddeley A., Gathercole, S.E., \& Papagno, C. (1998). The phonological loop as a language learning device. Psychological Review, 105, 158-173.

Baddeley, A., Papagno C., \& Vallar G. (1988). When long-term learning depends on shortterm storage. Journal of Memory and Language, 27, 586-595.

Badian, N.A. (1995). Predicting reading ability over the long term: The changing roles of letter naming, phonological awareness and orthographic processing. Annals of Dyslexia, 45 , 79-96.

Badian, N. (2000). Do preschool orthographic skills contribute to prediction or reading? In N.A. Badian (ed.), Prediction and prevention of reading failure (pp. 31-56). Baltimore, MD: York Press.

Badian, N. (2001). Phonological and orthographic processing: Their roles in reading prediction. Annals of Dyslexia, 51, 179-202.

Bailey, C.E., Manis, F.R., Pedersen, W.C., \& Seidenberg, M.S. (2004). Variation among developmental dyslexics: Evidence from a printed-word-learning task. Journal of Experimental Child Psychology, 87, 125-154.

Brady, S.A. (1991). The role of working memory in reading disability. In S. A. Brady \& D.

P. Shankweiler (Eds.), Phonological processes in literacy: A tribute to Isabelle Y. Liberman (pp.129-151). Hillsdale, NJ: Erlbaum.

Bruck, M. (1993). Component spelling skills of college students with a childhood diagnosis of dyslexia. Learning Disability Quarterly, 16, 171-184.

Bryden, M.P. (1972). Auditory-visual and sequential matching in relation to reading ability. Child Development, $\underline{43}$, 824-832. 
Bus, A., \& van Ijsendoorn, M. (1999). Phonological awareness and early reading: A metaanalysis of experimental training studies. Journal of Educational Psychology, 91, 403414.

Campbell, R., \& Butterworth, B. (1985). Phonological dyslexia and dysgraphia in a highly literate subject: A developmental case with associated deficits of phonemic processing and awareness. The Quarterly Journal of Experimental Psychology, 37A, 435-475.

Castles, A, \& Coltheart, M. (1993). Varieties of developmental dyslexia. Cognition, 47, 149180.

Castles, A., \& Coltheart, M. (1996). Cognitive correlates of developmental surface dyslexia: A single case study. Cognitive Neuropsychology, $\underline{13}, 25-50$.

Castle, A., \& Holmes, V.M. (1996). Subtypes of developmental dyslexia and reading acquisition. Australian Journal of Psychology, $\underline{48}$, 130-135.

Colheart, M., Curtis, B., Atkins, P., \& Haller, M. (1993). Models of reading aloud: Dual route approaches and parallel-distributed processing approaches. $\underline{\text { Psychological }}$ $\underline{\text { Review, }} \underline{100}$, 589-608.

Corkin, S. (1974). Serial-ordering deficits in inferior readers. Neuropsychologia, 12, 347-354.

Cunningham, A.E., Perry, K. E., Stanovich, K.E., \& Share, D.L. (2002). Orthographic learning during reading: examining the role of self teaching. Journal of Experimental Child Psychology, 82, 185-199.

Cunningham, A.E., \& Stanovich, K.E. (1993). Children's literacy environment and early word recognition skills. Reading and Writing: An Interdisciplinary Journal, $\underline{5}$, 193-204.

de Jong, P.F., Seveke, M-J, \& van Veen, M. (2000). Phonological sensitivity and the acquisition of new words in children. Journal of Experimental Child Psychology, 76, 275-301.

de Jong, P.F., \& van der Leij, A. (1999). Specific contributions of phonological abilities to early reading acquisition: Results from a Dutch latent variable longitudinal study. Journal of Educational Psychology, 91 , 450-476.

Ehri, L.C. (1992). Reconceptualizing the development of sight word reading and its relationship to decoding. In P.B. Gough, L. C. Ehri, \& R. Treiman (Eds.), Reading Acquisition (pp.107-143). Hillsdale, NJ: Erlbaum. 
Ehri, L.C. (1998). Phases of word learning: Implications for instruction with delayed and disabled readers. Reading and Writing Quarterly: Overcoming Learning Difficulties, 14 , 135-163.

Ehri, L.C., Nunes, S.R., Willows, D.M., Valeska Schuster, B., Yaghoub-Zadeh, Z., \& Shanahan, T. (2001). Phonemic awareness instruction helps children to learn to read: Evidence from the National Reading Panel's meta-analysis. Reading Research Quarterly, 36, 250-287.

Ehri, L.C., \& Saltmarsh, J. (1995). Beginning readers outperform older disabled readers in learning to read words by sight. Reading and Writing: An Interdisciplinary Journal, $\underline{7}$, 295-326.

Elbro, C., Borstrom, I., \& Petersen, D. K. (1998). Predicting dyslexia from kindergarten: The importance of distinctness of phonological representations of lexical items. Reading Research Quarterly, 33, 36-60.

Ellis, N.C., \& Miles, T.R. (1981). A lexical encoding deficiency II. In G.Th. Pavlidis and Miles T.R. (Eds), Dyslexia research and its applications to education. Cambridge, Mass.: MIT Press.

Farmer, M.E., \& Klein, R.M. (1995). The evidence for a temporal processing deficit linked to dyslexia: A review. Psychonomic Bulletin \& Review, 2, 460-493.

Fildes, L.G. (1921). Psychological inquiry into the nature of the condition known as congenital word-blindness. Brain, $\underline{44}, 286-307$.

Freedman, M.L., \& Martin, R.C. (2001). Dissociable components of short-term memory and their relation to long-term learning. Cognitive Neuropsychology, 18, 193-226.

Frith, U. (1985). Beneath the surface of developmental dyslexia. In K. Patterson, J. Marshall, $\&$ M. Coltheat (Eds.), Surface Dyslexia. London: Erlbaum.

Funnel, E., \& Davison, M. (1989). Lexical capture: A developmental disorder of reading and spelling. The Quarterly Journal of Experimental Psychology, 41A, 471-487.

Gallagher, A., Frith, U., Snowling, M.J. (2000). Precursors of literacy delay among children at genetic risk of dyslexia. Journal of Child Psychology and Psychiatry and Allied Disciplines, $\underline{41}, 203-213$.

Gascon, G., \& Goodglass, H. (1970). Reading retardation and the information content of stimuli in paired associate learning. Cortex, $\underline{6}, 417-429$. 
Gathercole, S.E., \& Baddeley, A.D. (1990). The role of phonological memory in vocabulary acquisition: A study of young children learning new names. British Journal of Psychology, $\underline{81}, 439-454$.

Gathercole, S. E., Hitch, G.J., Service, E., \& Martin, A.J. (1997). Phonological short-term memory and new word learning in children. Developmental Psychology, 33, 966-979.

Goswami, U., \& Bryant, P. (1990). Phonological skills and learning to read. London: Erlbaum.

Goulandris, N.K., \& Snowling, M. (1991). Visual memory deficits: A plausible cause of developmental dyslexia? Evidence from a single case study. Cognitive Neuropsychology, $\underline{8}, 127-154$.

Griffith, P. (1991). Phonemic awareness helps first graders invent spellings and third graders remember correct spellings. Journal of Reading Behavior, 23, 215-233.

Griffiths, Y. \& Snowling, M.J. (2002). Predictors of exception word and non-word reading in dyslexic children: The severity hypothesis. Journal of Educational Psychology, 94, 3443.

Hanley, J.R., Hastie, K., \& Kay, J. (1992). Developmental surface dyslexia and dysgraphia: An orthographic processing impairment. The Quarterly Journal of Experimental Psychology, 44A, 285-319.

Hanten, G., \& Martin, R.C. (2001). A developmental phonological short-term memory deficit; A case study. Brain and Cognition, $\underline{45}, 164-188$.

Harm, M.W., \& Seidenberg, M.S. (1999). Phonology, reading acquisition, and dyslexia: Insights from connectionist models. Psychological Review, 106, 491-528.

Holmes, V.M., \& Castles, A. E. (2001). Unexpectedly poor spelling in university students. Scientific Studies of Reading, $\underline{5}, 319-359$.

Holmes, V.M., \& Ng, E. (1993). Word-specific knowledge, word-recognition strategies and spelling ability. Journal of Memory and Language, $\underline{32}$, 230-257.

Holmes, V.M., \& Standish, J.M. (1996). Skilled reading with impaired phonology: A case study. Cognitive Neuropsychology, $\underline{13}, 1207-1222$.

Howard, D., \& Best, W. (1997). Impaired non-word reading with normal word reading: a case study. Journal of Research in Reading, 20, 55-65.

Jorm, A.F. (1983a). Specific reading retardation and working memory: A review. British Journal of Psychology, 74, 311-342. 
Jorm, A.F. (1983b). The psychology of reading and spelling disabilities. London: Routledge and Kegan Paul.

Kay, J., Lesser, R., \& Coltheart, M. (1992). PALPA: Psycholinguistic assessment of language processing in aphasia. London: Lawrence Earlbaum Associates.

Leong, C. (1999). Phonological coding and children's spelling. Annals of Dyslexia, $\underline{49}, 195-$ 220.

Lovegrove, B. (1996). Dyslexia and a transient/magnocellular pathway deficit: The current situation and future directions. Australian Journal of Psychology, 48, 167-171.

Manis, F.R., Savage, P.L., Morrison, F.J., Horn C.C., Howell M.J., Szeszulski P.A., \& Holt L.K. (1987) Paired associate learning in reading-disabled children: Evidence for a rulelearning deficiency. Journal of Experimental Child Psychology, 45, 25-43.

Mason, M. (1980). Reading ability and the encoding of item and location information. Journal of Experimental Psychology: Human Perception and Performance, $\underline{6}$, 89-98.

Mayringer, H., \& Wimmer, H. (2000). Pseudoname learning by German-speaking children with dyslexia: Evidence for a phonological learning deficit. Journal of Experimental Child Psychology, 75, 116-133.

McDougall, S., Hulme, C., Ellis, A., \& Monk, A. (1994). Learning to read: The role of shortterm memory and phonological skills. Journal of Experimental Psychology, 58, 112 133.

Messbauer, V.C.S., \& de Jong, P.F. (2003). Word, nonword, and visual paired associate learning in Dutch dyslexic children. Journal of Experimental Child Psychology, $\underline{\text { 84, }} 77$ 96.

Michas, I.C., \& Henry, L.A. (1994). The link between phonological memory and vocabulary acquisition. British Journal of Developmental Psychology, 12, 147-163.

Nation, K., \& Snowling, M.J. (1998). Semantic processing and the development of wordrecognition skills: Evidence from children with reading comprehension difficulties. Journal of Memory and Language, 39, 85-101.

Nelson, H.E. (1991). National Adult Reading Test. Second Edition. Oxford, UK: The NFERNelson Publishing Company.

Nelson, H.E., \& Warrington, E. (1980). An investigation of memory functions in dyslexic children. British Journal of Psychology, 71, 487-503. 
Otto, W. (1961). The acquisition and retention of paired associates by good, average, and poor readers. Journal of Educational Psychology, 52, 241-248.

Papagno, C., Valentine T., \& Baddeley A. (1991). Phonological short-term memory and foreign-language vocabulary learning. Journal of Memory and Language, $\underline{30}$, 331-347.

Papagno, C., \& Vallar, G. (1992). Phonological short-term memory and the learning of novel words: The effect of phonological similarity and item length. The Quarterly Journal of Experimental Psychology, 44A, 47-67.

Perin, D. (1983). Phonemic segmentation in spelling. British Journal of Psychology, $\underline{74}, 129$ 144.

Plaut, D.C., MClelland, J.L., Seidenberg, M.S., \& Patterson, K. (1996). Understanding normal and impaired reading: Computational principles in quasi-regular domains. Psychological Review, 103, 56-115.

Rack, J.P., Hulme, C., \& Snowling, M.J. (1993). Learning to read: A theoretical synthesis. In: H. Reese (Ed.), Advances in child development and behaviour (pp. 100-128). San Diego, California: Academic Press.

Reitsma, P. (1983). Printed word learning in beginning readers. Journal of Experimental Child Psychology, 36, 321-339.

Reitsma, P. (1989). Orthographic memory and learning to read. In: P.G.Aaron \& R.M. Joshi (eds.), Reading and writing disorders in different orthographic systems (pp. 51-73). Kluwer Academic Publishers.

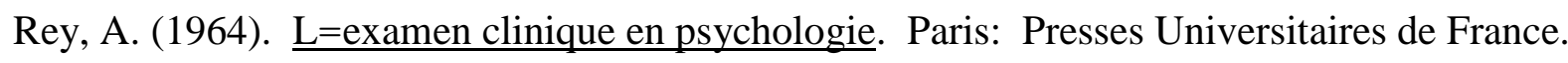
Romani, C., \& Stringer, M. (1994). Developmental dyslexia: A problem acquiring orthographic/phonological information in the face of good visual memory and shortterm memory. Brain and Language, $\underline{57}, 482-485$.

Romani, C., Ward, J., \& Olson, A. (1999). Developmental surface dysgraphia: What is the underlying cognitive impairment? The Quarterly Journal of Experimental Psychology, 52A, 97-128.

Schonell, F.J. (1985). Essentials in Teaching and Testing Spelling (revised by Wise P.), McMillan Education Ltd.

Seidenberg M.S. \& McClelland J.L. (1989). A distributed, developmental model of word recognition and naming. Psychological Review, 96, 523-568.

Seidenberg, M.S., Waters, G.S., \& Barnes, M.A. (1984). When does irregular spelling or 
pronunciation influence word recognition? Journal of Verbal Learning and Verbal Behavior, 23, 383-404.

Seymour, P.H.K. \& MacGregor, C.J. (1984). Developmental dyslexia: A cognitive experimental analysis of phonological, morphemic, and visual impairments. Cognitive Neuropsychology, 1, 43-82.

Share, D.L., \& Stanovich, K.E. (1995). Cognitive processes in early reading development: Accomodating individual differences in a model of acquisition. Issues in Education, $\underline{1}$, $1-57$.

Snowling, M. (2000). Dyslexia (2 ${ }^{\text {nd }}$ ed.). Oxford: Blackwell Publishers.

Snowling, M., \& Hulme, C. (1989). A longitudinal case study of developmental phonological dyslexia. Cognitive Neuropsychology, $\underline{6}, 379-401$.

Snowling, M., Stackhouse, J., \& Rack, J.P. (1986). Phonological dyslexia and dysgraphia: A developmental analysis. Cognitive Neuropsychology, $\underline{3}, 309-339$.

Stackhouse, J. (1996). Speech, spelling and reading: who is at risk and why? In M. Snowling \& J. Stackhouse (Eds), Dyslexia, speech and language. A practitioner's handbook (pp. 12-30). London, England: Whurr Publishers Ltd.

Stanovich, K. E (1992). Speculations on the causes and consequences of individual differences in early reading acquisition. In P. B. Gough, L.C. Ehri, \& R. Treisman (Eds.), Reading acquisition (pp. 307-342). Hillsdale, NJ: Lawrence Erlbaum Associates.

Stanovich, K.E. (2000). Progress in understanding reading: Scientific foundations and new frontiers. New York: The Guilford Press.

Stanovich, K.E., Siegel, L.S., \& Gottardo (1997). Converging evidence for phonological and surface subtypes of reading disability. Journal of Educational Psychology, $\underline{89}$ (1)., 114-127

Stanovich, K.E., \& West R.F. (1989). Exposure to print and orthographic processing. Reading Research Quarterly, 24, 402-429.

Stothard, S.E., Snowling, M.J., \& Hulme, C. (1996). Deficits in phonology, but not dyslexics? Cognitive Neuropsychology, 13 (5), 641-672.

Torgesen, J.K., Morgan, S.T., \& Davis, C. (1992). Effects of two types of phonological awareness training on word learning in kindergarten children. Journal of Educational Psychology, 4ㅗ , 3, 364-370. 
Vellutino, F.K., \& Scanlon, D.M. (1985). Free recall of concrete and abstract words in poor and normal readers. Journal of Experimental Child Psychology, 39, 363-380.

Vellutino, F.R., Scanlon, D.M., \& Spearing, D. (1995). Semantic and phonological coding in poor and normal readers. Journal of Experimental Child Psychology, 59, 76-123.

Vellutino, F.R., Steger, J.A., \& Pruzek, R. M. (1973). Inter- vs intra-sensory deficit in pairedassociate learning in poor and normal readers. Canadian Journal of Behavioral Science, $\underline{5}, 111-123$.

Vellutino, F.R., Steger, J.A., Harding, C.J., \& Phillips, F. (1975). Verbal vs non-verbal paired associates learning in poor and normal readers. Neuropsychologia, $\underline{13}, 75-82$.

Wagner, R.K., \& Torgesen, J.K. (1987). The nature of phonological processing and its causal role in the acquisition of reading skills. Psychological Bulletin, 101, 192-212.

Wechsler, D. (1981). Wechsler adult intelligence scale (revised ed.). New York: The Psychological Corporation, Harcourt Brace Jovanovich, Inc.

Wechsler, D. (1987). Wechsler memory scale (revised ed.). New York: The Psychological Corporation, Harcourt Brace Jovanovich, Inc.

Wimmer, H., Mayringer, H., \& Landerl, K., (1998). Poor reading: A deficit in skillautomatization or a phonological deficit? Scientific Studies of Reading, 2, 321-340.

Windfuhr, K.L., \& Snowling, M. (2001). The association between paired associate learning and phonological skills in normally developing readers. Journal of Experimental Child Psychology, 80, 160-173.

Wolf, M., Bowers, P., \& Biddle, K. (2000). Naming speed processes, timing, and reading: A conceptual review. Journal of Reading Disabilities, $\underline{33}, 387-407$.

(a)

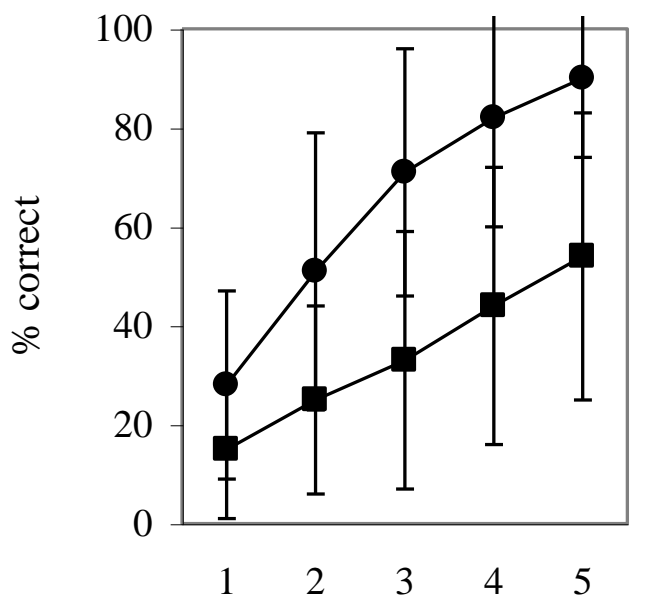

(b)

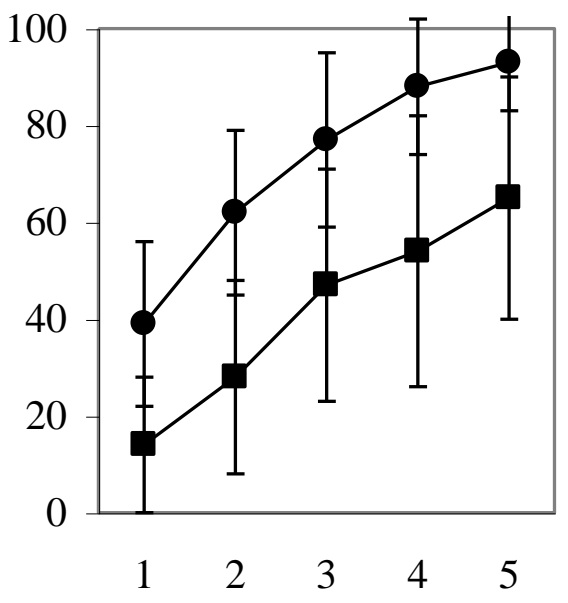


(c)

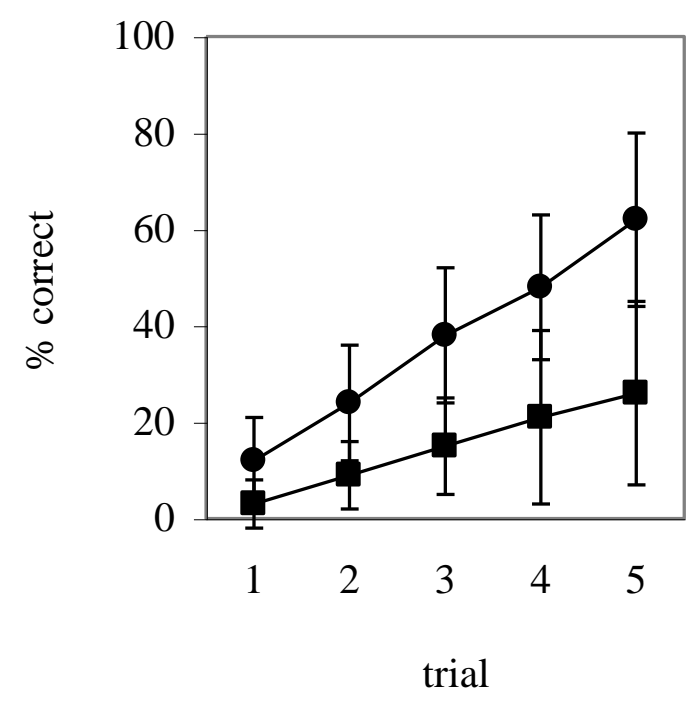

(d)

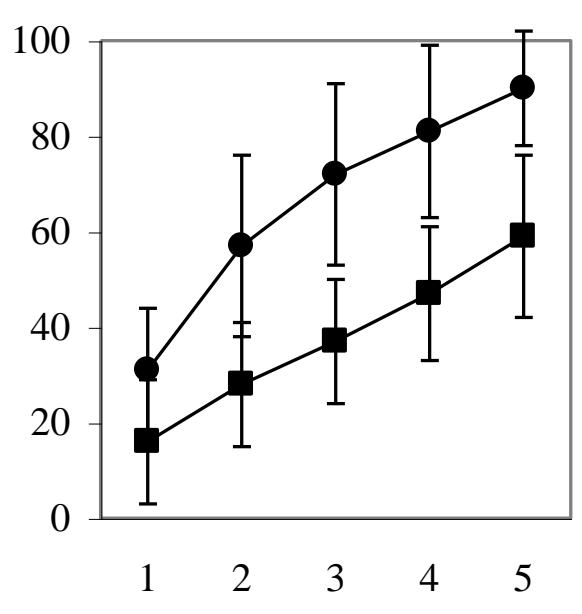

trial

Controls

Dyslexics 


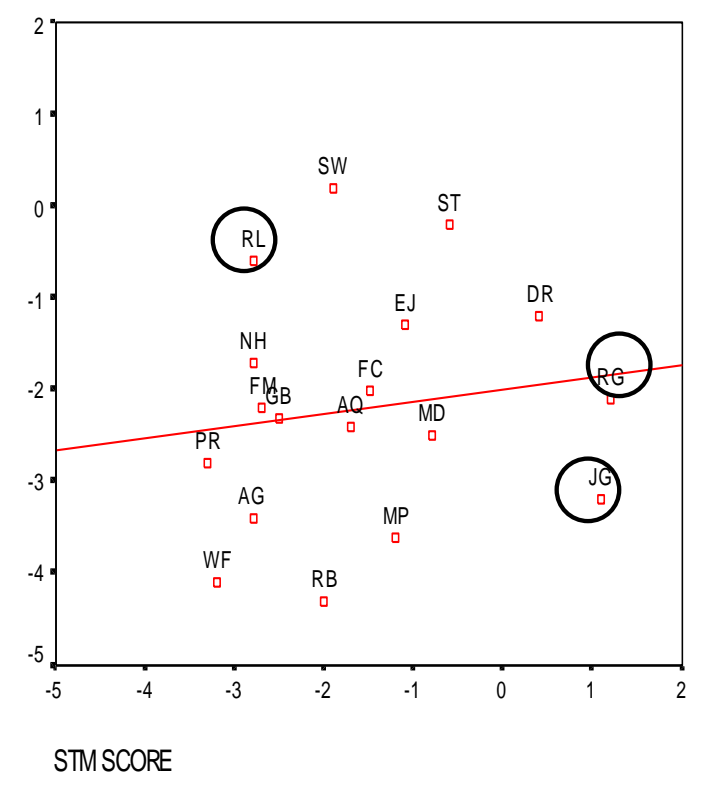

O

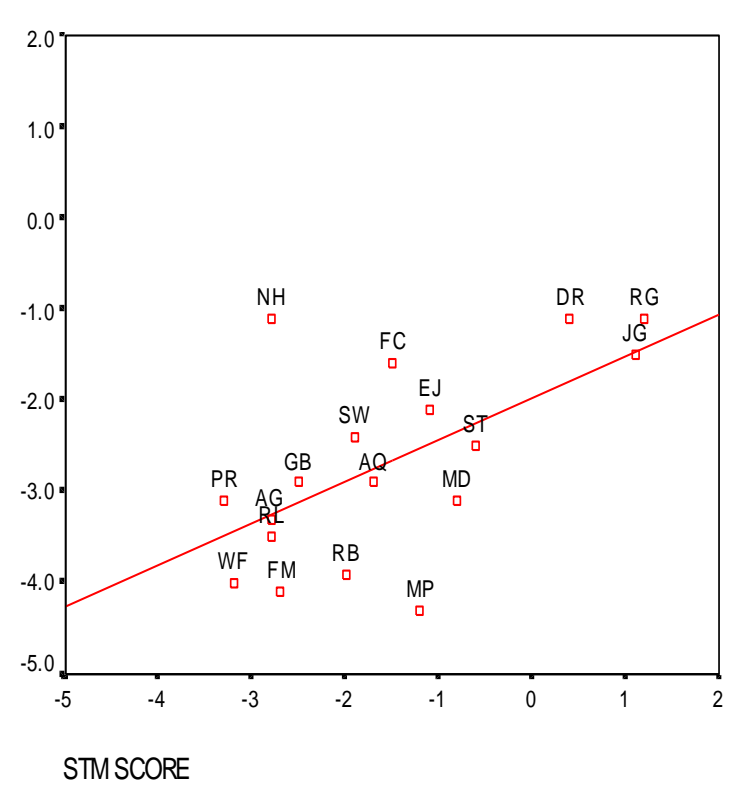



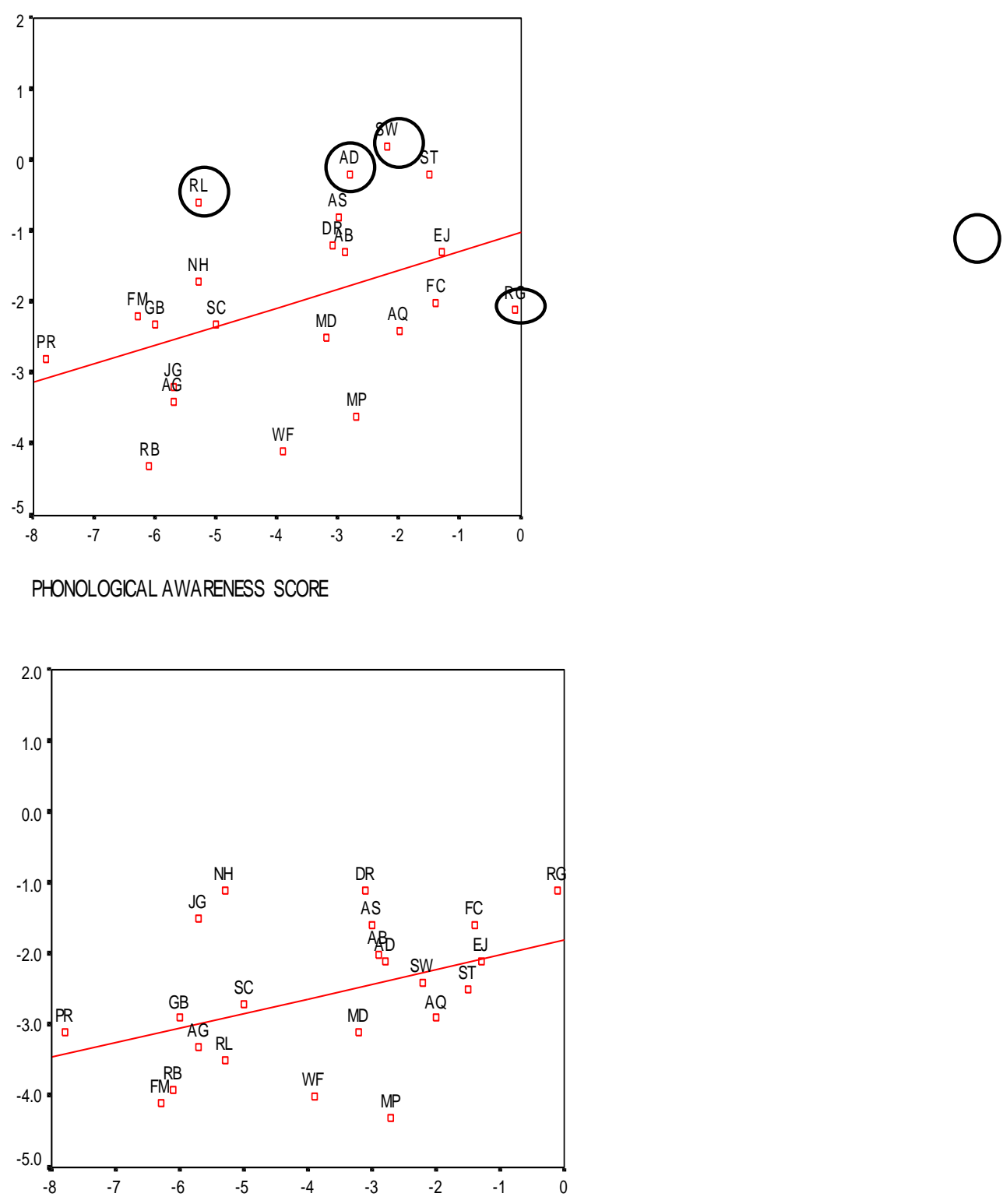

PHONOLOGICAL AW ARENESS SCORE 